BNL-108584-2015-JA

\title{
Boosting the electron mobility of solution-grown organic single crystals via reducing the amount of polar solvent residues $\dagger$
}

\author{
Guobiao Xue, ${ }^{\mathrm{a}}$ Jiake Wu, ${ }^{\mathrm{a}}$ Congcheng Fan, ${ }^{\mathrm{a}}$ Shuang Liu, ${ }^{\mathrm{a}}$ Zhuoting Huang, ${ }^{\mathrm{a}}$ Yujing Liu, ${ }^{\mathrm{ab}}$ Bowen \\ Shan, ${ }^{\mathrm{c}}$ Huolin L Xin, ${ }^{\mathrm{b}}$ Qian Miao, ${ }^{\mathrm{c}}$ Hongzheng Chen, ${ }^{\mathrm{a}}$ and Hanying Li ${ }^{\mathrm{a}}$
}

\begin{abstract}
Enhancing the electron transport to match up with the hole transport developed far ahead is critical for organic electronics. As electron motion is susceptible to extrinsic factors, to seek these factors and to avoid their negative effects become the central challenge. Here, the existence of polar solvent residues in solution-grown single-crystals of $6,13-$ bis(triisopropylsilylethynyl)-5,7,12,14-tetraazapentacene is identified as a factor detrimental to electron motion. Field-effect transistors of the crystals exhibit electron mobility boosted up by about $60 \%$ after the residues are removed. The average electron mobility reaches up to $8.0 \pm 2.2 \mathrm{~cm}^{2} \mathrm{~V}^{-1} \mathrm{~s}^{-1}$ with the highest value of $13.3 \mathrm{~cm}^{2} \mathrm{~V}^{-1} \mathrm{~s}^{-1}$, significantly higher than those obtained previously for the same molecule $\left(1.0-5.0 \quad \mathrm{~cm}^{2} \quad \mathrm{~V}^{-1} \mathrm{~s}^{-1}\right)$. Furthermore, the achieved mobility is also higher than the maximum reported electron mobility for organic materials (11 $\left.\mathrm{cm}^{2} \mathrm{~V}^{-1} \mathrm{~s}^{-1}\right)$. This work should greatly accelerate the advance of organic electron-transporting materials.
\end{abstract}

Conceptual Insights: Solution processability is widely believed to be a critical advantage of organic semiconductors and solvent residues in the processed thin films and crystals are inevitable. This work shows that trace amount of polar solvent residues in solution-grown single-crystals is detrimental to electron motion. Removing these residues leads to an increase of electron mobility by about $60 \%$. Using this strategy, a record high electron mobility among organic materials, $13.3 \mathrm{~cm}^{2} \mathrm{~V}^{-1} \mathrm{~s}^{-1}$, is achieved in solution-grown TIPS-TAP single crystals. The negative solvent effect on the electron transport shown in this work has the potential to greatly advance the development of

\footnotetext{
${ }^{a}$ MOE Key Laboratory of Macromolecule Synthesis and Functionalization, State Key Laboratory of Silicon Materials, Department of Polymer Science and Engineering, Zhejiang University, Hangzhou, 310027, P. R. China. E-mail: hanying_li@zju.edu.cn

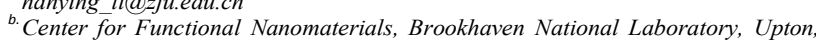
NY 11973, USA

c. Center of Novel Functional Molecules, Department of Chemistry Laboratory, The Chinese University of Hong Kong, Shatin, New Territories, Hong Kong, P. R. China

$\dagger$ Electronic Supplementary Information (ESI) available. See
} DOI: $10.1039 / \mathrm{x} 0 \times x \times 0000 \mathrm{x}$ high-performance n-type organic semiconductors.

Hole and electron transports in organic semiconductors are equally important for double-carrier electronic devices, such as complementary circuits, ${ }^{1}$ solar cells, ${ }^{2}$ and light-emitting diodes. ${ }^{3}$ However, the overall developments in organic hole and electron transporting materials are not parallel with the electron side lagging far behind, as clearly seen from the comparison of the hole and electron field-effect mobility. ${ }^{4-7}$ Currently, hole mobility above $10 \mathrm{~cm}^{2} \mathrm{~V}^{-1} \mathrm{~s}^{-1}$ has been achieved in a variety of organic materials including both small molecules and polymers. $^{8-21}$ In sharp contrast, electron mobility $\left(\mu_{\mathrm{e}}\right)$ approaching $10 \mathrm{~cm}^{2} \mathrm{~V}^{-1} \mathrm{~s}^{-1}$ is not often reported. .2-32 $^{2}$ Intrinsically, organic semiconductors should provide an equal opportunity for both charges. ${ }^{33}$ The underdeveloped electron transport performance of organic materials indicates that the intrinsic properties must be masked by extrinsic factors. As such, the development of organic electron-transporting materials lies greatly in the discovering and eliminating the extrinsic factors detrimental to electron motion.

Field-effect transistors (FETs) are widely used to study the hole transport ( $\mathrm{p}$-channel) and electron transport (n-channel) properties of organic semiconductors. ${ }^{34}$ The well-known obstacles to electron conductance in an organic n-channel FET have been recognized to be associated with high electron injection barriers, ${ }^{33,35}$ electron traps induced by $\mathrm{O}_{2}$ and $\mathrm{H}_{2} \mathrm{O}$, ${ }^{4,36}$ traps at the semiconductor-dielectric interface, ${ }^{37}$ and the polarizable environment near the moving electrons. ${ }^{25}$ Accordingly, efforts have been made to reduce the effect of these extrinsic factors through varied strategies. Improving the charge injection has been widely used through either selecting proper electrodes ${ }^{22,27,38-43}$ such as low work-function metals or enhancing the electron affinity of organic semiconductors. ${ }^{28,44-}$ 46 On the other hand, eliminating electron traps (such as hydroxyl groups) on the dielectrics ${ }^{37}$ greatly improved the electron transport of organic semiconductors. In addition to the above factors impeding the electron motion, we found, ${ }^{47}$ very recently, a solvent effect on the n-channel behaviors. For 6,13bis(triisopropyl-silylethynyl)pentacene (TIPS-pentacene), ${ }^{48}$ a standard p-channel material, electron transport emerges in their 
single crystals grown from non-polar solvents but is suppressed in those from polar solvents. The distinct electronic properties induced by the different solvents are not associated with the change of molecular packing ${ }^{16,17,49}$ or the doping in the semiconductor, ${ }^{27,50,51}$ but, instead, imply that trace amounts of polar solvents residues in the crystals ruin the electron conductance. In context of this result, we envision that similar solvent effect should exist in solution-grown n-channel material and by proper selection of the used solvents to avoid polar solvents residues, enhancement of the electron transport is expected. In this work, we investigated the electron transport of 6,13-bis(triisopropylsilylethynyl)-5,7,12,14-tetraazapentacene (TIPS-TAP, Fig. 1b inset), a soluble n-channel material exhibiting $\mu_{\mathrm{e}}$ between $1.0-5.0 \mathrm{~cm}^{2} \mathrm{~V}^{-1} \mathrm{~s}^{-1}$ in the previous reports. $^{31,45,52,53}$ By reducing the amount of the polar solvent residues in the TIPS-TAP single crystals, $\mu_{\mathrm{e}}$ was boosted up to $13.3 \mathrm{~cm}^{2} \mathrm{~V}^{-1} \mathrm{~s}^{-1}$ with an average value of $8.0 \pm 2.2 \mathrm{~cm}^{2} \mathrm{~V}^{-1} \mathrm{~s}^{-1}$.

A direct method to avoid polar solvents residues in the crystals is to use non-polar solvents for crystallization. As a typical non-polar solvent, hexane was selected to grow TIPSTAP single crystals using the droplet-pinned crystallization method, ${ }^{24,54}$ a facile solution processing approach to prepare well-aligned single crystals of a variety of organic semiconductors. ${ }^{55,56}$ The crystals were directly grown on divinyltetramethyldisiloxane-bis(benzocyclobutene) (BCB)covered $\mathrm{SiO}_{2} / \mathrm{Si}$ substrates where the BCB layer ( $\sim 10 \mathrm{~nm}$ thick) was found to efficiently eliminate the electron traps on $\mathrm{SiO}_{2}{ }^{37}$ so that electron transport can be well examined. Well-aligned long ribbons of several hundred micrometers in length were obtained (Fig. 1a and Fig. S1 $\dagger$ ). Atomic force microscopy (AFM) images of the ribbons show a thickness of 18.9-78 nm and width of 1.5-12.9 $\mu \mathrm{m}$. The same color of individual ribbons

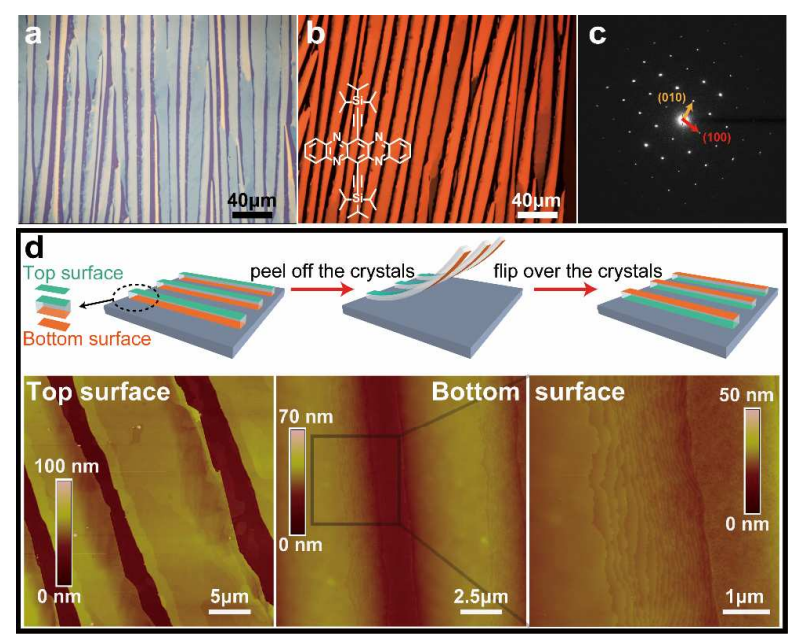

Fig. 1 Morphology and crystalline structure of crystals grown from hexane solutions. (a) An optical microscopy (OM) image of the crystals. (b) An OM image of the crystals between crossed-polarizers. Inset: structure of TIPS-TAP. (c) An SAED pattern of the crystal. (d) Schematic representations showing the top and bottom surfaces of the crystals and AFM images of the crystals. between crossed-polarizers indicates their single-crystallinity (Fig. 1b). A selected-area electron diffraction (SAED) pattern confirms the single crystal nature by showing a single set spots with a crystallographic structure consistent with the previous report (Fig. 1c). ${ }^{52}$

Based on these aligned single crystals, FETs were constructed by depositing Au source and drain electrodes using a shadow mask in a top-contact, bottom-gate configuration (Fig. 2a). As the crystals did not cover the channel region completely, the real channel length $(L)$ and width $(W)$ were measured (Fig. 2b) instead of using the channel dimensions of the shadow mask $(L: 50 \mu \mathrm{m} ; W: 1 \mathrm{~mm})$. FETs characteristics were investigated in a $\mathrm{N}_{2}$ glovebox and saturation regime $\mu_{\mathrm{e}}$ was calculated for 50 devices. The typical transfer and output characteristics are shown in Fig. 2c,d, exhibiting excellent gate modulation. An average $\mu_{\mathrm{e}}$ of $5.3 \pm 1.2 \mathrm{~cm}^{2} \mathrm{~V}^{-1} \mathrm{~s}^{-1}$ (range: 2.7 to $8.4 \mathrm{~cm}^{2} \mathrm{~V}^{-1} \mathrm{~s}^{-1}$, Fig. 2e), on-to-off current radio $\left(I_{\mathrm{on}} / I_{\mathrm{off}}\right)>10^{5}$, and threshold voltages $\left(V_{\mathrm{T}}\right)$ between 45 and $72 \mathrm{~V}$ were obtained.

The achieved $\mu_{\mathrm{e}}$ is significantly higher than the reported values (1.0-5.0 $\left.\mathrm{cm}^{2} \mathrm{~V}^{-1} \mathrm{~s}^{-1}\right)$ for the same molecule, TIPSTAP. ${ }^{31,45,52,53}$ In the previous reports, polar solvents such as chlorobenzene, dichloromethane $\left(\mathrm{CH}_{2} \mathrm{Cl}_{2}\right)$ and acetone were used to prepare the $n$-channel materials of TIPS-TAP. The non-
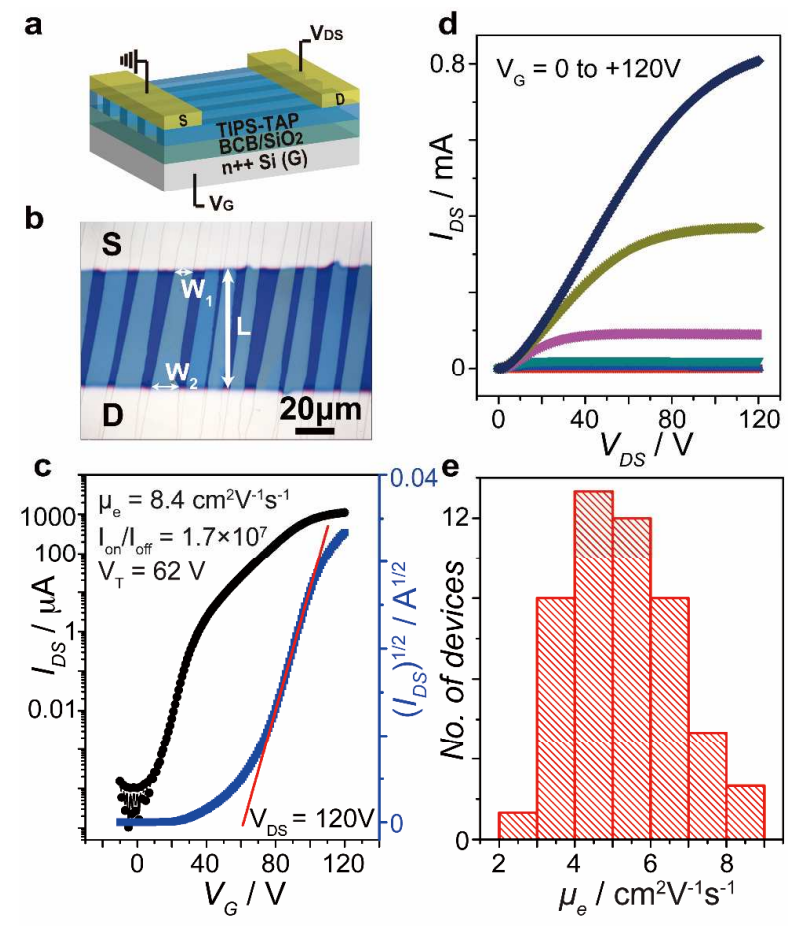

Fig. 2 FET characteristics of crystals grown from hexane solutions. (a) A schematic representation of the FET configuration, where $\mathrm{S}$ is the source, D the drain and G the gate. (b) An OM image showing the method of $W / L$ measurement. $L$ was measured from the real channel length and $W$ was measured from the contacting area of the crystals that cross the $\mathrm{S}$ and $\mathrm{D}$ electrodes. $W$ was calculated by the 
equation: $W=\Sigma\left(W_{1}+W_{2}\right) / 2$. (c,d) Typical transfer and output characteristics of the FETs. (e) Histogram of the $\mu_{\mathrm{e}}$ of 50 FETs. polar solvent, hexane, used in the current work and the resulting superior $\mu_{\mathrm{e}}$ might imply a negative effect of polar solvent residues on the electron transport.

Despite the high $\mu_{\mathrm{e}}$ up to $8.4 \mathrm{~cm}^{2} \mathrm{~V}^{-1} \mathrm{~s}^{-1}$, the poor morphologies of the crystals revealed by AFM (Fig. 1d) indicate a possibility to further improve the electron transport. AFM imaging on the top surfaces of the crystals shows relative rough features instead of smooth terraces. More importantly, the bottom surfaces of the crystals where the electron transport channel locates are also rough with steps. The rough bottom surfaces lead to non-intimate interfaces with the substrates, affecting adversely the electron transport. The formation of rough surfaces is associated with the fast crystallization mainly due to the low solubility (about $0.4 \mathrm{mg} / \mathrm{mL}$ ) of TIPS-TAP in hexane. And solvents allowing higher solubility may result in smoother surfaces during slower crystallization. In addition to hexane, other solvents were examined. Non-polar solvents including cyclohexane, heptane, octane and nonane showed very low solubility below $1 \mathrm{mg} / \mathrm{mL}$. Alternatively, polar solvents such as $\mathrm{CH}_{2} \mathrm{Cl}_{2}$ and chloroform $\left(\mathrm{CHCl}_{3}\right)$ with much higher solubility were selected and a heat-treatment was used to reduce the amount of the polar solvent residues in the solutiongrown crystals.

Crystallization from $\mathrm{CH}_{2} \mathrm{Cl}_{2}$ solutions was first studied. The crystals were expressed by rough surfaces associated with the fast solvent evaporation and crystallization due to the highly volatile nature of $\mathrm{CH}_{2} \mathrm{Cl}_{2}$ (Fig. S2a,b $\dagger$ ). Relatively low $\mu_{\mathrm{e}}$ of 2.2 $\pm 0.8 \mathrm{~cm}^{2} \mathrm{~V}^{-1} \mathrm{~s}^{-1}$ (range: 1.0 to $4.4 \mathrm{~cm}^{2} \mathrm{~V}^{-1} \mathrm{~s}^{-1}$ ) for the asprepared crystals and $3.6 \pm 1.1 \mathrm{~cm}^{2} \mathrm{~V}^{-1} \mathrm{~s}^{-1}$ (range: 2.3 to $5.6 \mathrm{~cm}^{2}$ $\mathrm{V}^{-1} \mathrm{~s}^{-1}$ ) for heat-treated ones was obtained, respectively (Fig. S2e, f $\dagger$ ).

Next, $\mathrm{CHCl}_{3}$ with a boiling temperature higher than $\mathrm{CH}_{2} \mathrm{Cl}_{2}$ was examined. Delightedly, well-aligned ribbon-like crystals grown from $\mathrm{CHCl}_{3}$ solutions exhibited much smoother surfaces than those from $\mathrm{CH}_{2} \mathrm{Cl}_{2}$ and hexane (Fig. 3a-d). The AFM images show clearly the smooth top and bottom surfaces with rms roughness of $0.77 \mathrm{~nm}$ (top) and $0.50 \mathrm{~nm}$ (bottom), in sharp contrast to the rough features of those grown from hexane (rms roughness of $3.89 \mathrm{~nm}$ and $1.11 \mathrm{~nm}$ for the top and bottom surfaces, respectively, Fig. 1d). In addition, the crystals are wider $(10.1-26.8 \mu \mathrm{m})$, favoring charge injection. ${ }^{54}$ Similarly, the polarizing OM image (Fig. $3 \mathrm{~b}$ ) and the SAED pattern (Fig. 3e) exhibit the single-crystallinity and the crystallographic structure is consistent with those from hexane. X-ray photoelectron spectroscopy (XPS) analysis shows a peak of $\mathrm{Cl}$ $2 \mathrm{p}$, indicative of trace amount of the $\mathrm{CHCl}_{3}$ molecules in the asprepared crystals (Fig. S3a $\dagger$ ). In contrast, this peak is weaker and undetectable for the heated crystals (Fig. S3b †), indicating the removal of $\mathrm{CHCl}_{3}$ residues after heating. According to the SAED, the crystallographic structures before and after the heat treatment are identical (Fig. 3e,f).

After obtaining the single crystals with smooth surfaces using $\mathrm{CHCl}_{3}$, we proceeded to examine their charge transport properties. 124 FETs were fabricated and tested under $\mathrm{N}_{2}$ atmosphere before and after heat treatment at $100{ }^{\circ} \mathrm{C} .{ }^{57} \mathrm{Fig} .4 \mathrm{a}$

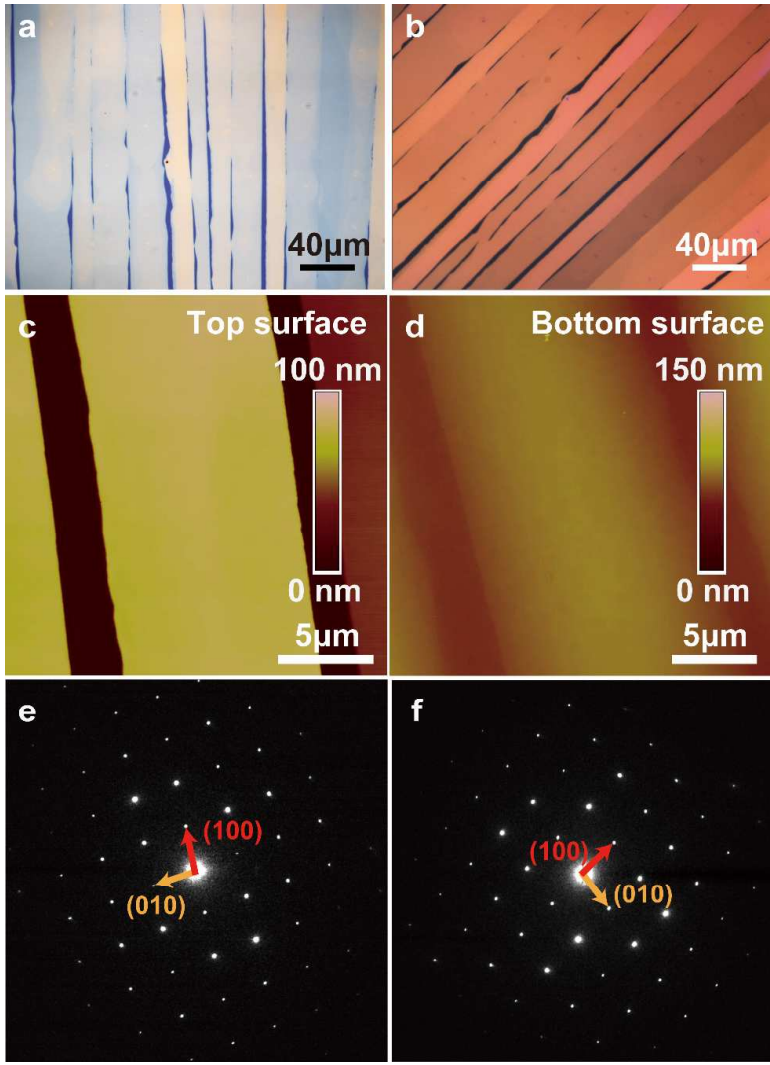

Fig. 3 Morphology and crystalline structure of crystals grown from $\mathrm{CHCl}_{3}$ solutions. (a) An $\mathrm{OM}$ image of the crystals. (b) An OM image of the crystals between crossed-polarizers with uniform brightness throughout the crystals. (c,d) AFM images of the crystals' top surface (c) and bottom surface (d). (e,f) SAED patterns of the crystals: (e) as-prepared; (f) heat-treated.

and c show the typical transfer and output characteristics of the devices, with excellent gate modulation. Before heating, an average $\mu_{\mathrm{e}}$ of $5.0 \pm 1.8 \mathrm{~cm}^{2} \mathrm{~V}^{-1} \mathrm{~s}^{-1}$ (Fig. 4e) was obtained, close to that of the crystals grown from hexane. In addition, $I_{\mathrm{on}} / I_{\mathrm{off}}$ was greater than $10^{5}$, and $V_{\mathrm{T}}$ was between 55 and $80 \mathrm{~V}$. After heating, each device exhibited an increase in $\mu_{\mathrm{e}}$, resulting in an average of $8.0 \pm 2.2 \mathrm{~cm}^{2} \mathrm{~V}^{-1} \mathrm{~s}^{-1}$ (range: $3.0 \mathrm{~cm}^{2} \mathrm{~V}^{-1} \mathrm{~s}^{-1}$ to 13.3 $\mathrm{cm}^{2} \mathrm{~V}^{-1} \mathrm{~s}^{-1}$, Fig. 4f). $I_{\text {on }} / I_{\text {off }}>10^{6}$, and $V_{\mathrm{T}}$ between 57 and $80 \mathrm{~V}$ were obtained. The $60 \%$ increase in the average $\mu_{\mathrm{e}}$ after heating and removal of the $\mathrm{CHCl}_{3}$ residues indicate their negative effect on the electron transport.

The $\mu_{\mathrm{e}}$ of $8.0 \pm 2.2 \mathrm{~cm}^{2} \mathrm{~V}^{-1} \mathrm{~s}^{-1}$ with the highest value of 13.3 $\mathrm{cm}^{2} \mathrm{~V}^{-1} \mathrm{~s}^{-1}$ is significantly higher than the maximum reported $\mu_{\mathrm{e}}$ (average $5.2 \pm 2.1 \mathrm{~cm}^{2} \mathrm{~V}^{-1} \mathrm{~s}^{-1}$ with the highest value of $11 \mathrm{~cm}^{2}$ $\left.\mathrm{V}^{-1} \mathrm{~s}^{-1}\right)^{24}$ for organic materials. Within the 124 devices, 29 ones exhibit $\mu_{\mathrm{e}}$ larger than $10 \mathrm{~cm}^{2} \mathrm{~V}^{-1} \mathrm{~s}^{-1}$. More importantly, the achieved $\mu_{\mathrm{e}}$ is also significantly higher than those obtained previously $\left(1.0-5.0 \mathrm{~cm}^{2} \mathrm{~V}^{-1} \mathrm{~s}^{-1}\right)$ for the same molecule, TIPSTAP. ${ }^{31,45,52,53}$ The higher mobility here is not only associated with the widely known factors including single-crystallinity, ${ }^{58}$ smooth and intimate contact with the substrate ${ }^{54}$ and the elimination of electron traps using $\mathrm{BCB}^{37}$ coating. In addition, 

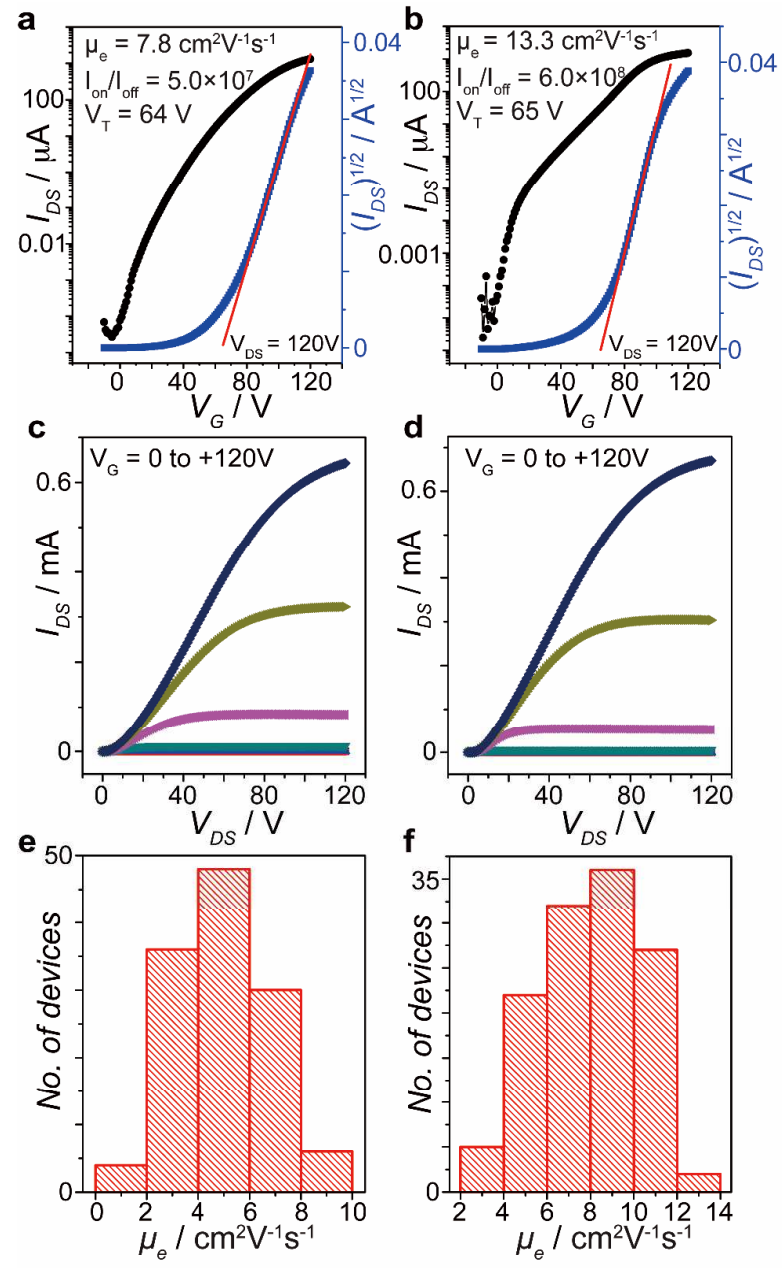

Fig. 4 FET characteristics of crystals grown from $\mathrm{CHCl}_{3}$ solutions. (a-d) Typical transfers and output characteristics of the FETs: $(a, c)$ as-prepared; (b,d) heat-treated. (e,f) Histograms of the $\mu_{\mathrm{e}}$ of 124 FETs: (e) as-prepared; (f) heat-treated.

the enhanced electron transport is attributed to the reduced polar solvent residues during the heat treatment. Upon heating, the crystallographic structure of the TIPS-TAP crystals remains unchanged (Fig. 3e,f), but the amount of polar solvent residues is dramatically reduced (Fig. S $3 \uparrow$ ) and the $\mu_{\mathrm{e}}$ increases by about $60 \%$ in both $\mathrm{CH}_{2} \mathrm{Cl}_{2}$ - and $\mathrm{CHCl}_{3}$-grown single crystals. As such, the existence of polar solvent residues in the TIPS-TAP crystals is identified as a factor detrimental to electron motion. ${ }^{47}$ As polarizable sources in or near the electron conducting channel, the polar solvent residues introduce energetic disorder and positional disorder that reduce the charge transport. ${ }^{59-62}$

\section{Conclusions}

In summary, we have demonstrated a record high $\mu_{\mathrm{e}}$ of 13.3 $\mathrm{cm}^{2} \mathrm{~V}^{-1} \mathrm{~s}^{-1}$ in solution-grown TIPS-TAP single crystals. The high mobility mainly results from reducing the amount of the polar solvent residues in the crystals by heat treatment that brings about $60 \%$ increase in mobility. Because solution processability is believed to be a critical advantage of organic semiconductors and the usage of varied solvents is needed, the negative solvent effect on the electron transport shown in this work has the potential to lead to design criteria for highperformance electron-transporting organic materials.

\section{Acknowledgements}

This work was supported by 973 Program (2014CB643503), National Natural Science Foundation of China (51222302, 51373150, 51461165301), Zhejiang Province Natural Science Foundation (LZ13E030002), and Fundamental Research Funds for the Central Universities. This research used the electron microscopy facility of the Center for Functional Nanomaterials, which is a U.S. DOE Office of Science Facility, at Brookhaven National Laboratory under Contract No. DE-SC0012704.

\section{Notes and references}

1 B. Crone, A. Dodabalapur, Y. Y. Lin, R. W. Filas, Z. Bao, A. LaDuca, R. Sarpeshkar, H. E. Katz and W. Li, Nature, 2000, 403, 521-523.

2 C. W. Tang, Appl. Phys. Lett., 1986, 48, 183-185.

3 C. W. Tang and S. A. Vanslyke, Appl. Phys. Lett., 1987, 51, $913-$ 915.

4 J. E. Anthony, A. Facchetti, M. Heeney, S. R. Marder and X. W. Zhan, Adv. Mater., 2010, 22, 3876-3892.

5 Y. Zhao, Y. L. Guo and Y. Q. Liu, Adv. Mater., 2013, 25, 53725391.

6 H. L. Dong, X. L. Fu, J. Liu, Z. R. Wang and W. P. Hu, Adv. Mater., 2013, 25, 6158-6183.

7 H. Sirringhaus, Adv. Mater., 2014, 26, 1319-1335.

8 V. Podzorov, E. Menard, A. Borissov, V. Kiryukhin, J. A. Rogers and M. E. Gershenson, Phys. Rev. Lett., 2004, 93, 086602 .

9 V. C. Sundar, J. Zaumseil, V. Podzorov, E. Menard, R. L. Willett, T. Someya, M. E. Gershenson and J. A. Rogers, Science, 2004, 303, 1644-1646.

10 O. D. Jurchescu, M. Popinciuc, B. J. van Wees and T. T. M. Palstra, Adv. Mater., 2007, 19, 688-692.

11 J. Takeya, M. Yamagishi, Y. Tominari, R. Hirahara, Y. Nakazawa, T. Nishikawa, T. Kawase, T. Shimoda and S. Ogawa, Appl. Phys. Lett., 2007, 90, 102120.

12 H. Minemawari, T. Yamada, H. Matsui, J. Tsutsumi, S. Haas, R. Chiba, R. Kumai and T. Hasegawa, Nature, 2011, 475, 364-367.

13 A. Y. Amin, A. Khassanov, K. Reuter, T. Meyer-Friedrichsen and M. Halik, J. Am. Chem. Soc., 2012, 134, 16548-16550.

14 J. Li, Y. Zhao, H. S. Tan, Y. L. Guo, C. A. Di, G. Yu, Y. Q. Liu, M. Lin, S. H. Lim, Y. H. Zhou, H. B. Su and B. S. Ong, Sci. Rep., 2012, 2, 754.

15 I. Kang, H. J. Yun, D. S. Chung, S. K. Kwon and Y. H. Kim, J. Am. Chem. Soc., 2013, 135, 14896-14899.

16 Y. Diao, B. C. K. Tee, G. Giri, J. Xu, D. H. Kim, H. A. Becerril, R. M. Stoltenberg, T. H. Lee, G. Xue, S. C. B. Mannsfeld and Z. N. Bao, Nat. Mater., 2013, 12, 665-671.

17 Y. B. Yuan, G. Giri, A. L. Ayzner, A. P. Zoombelt, S. C. B. Mannsfeld, J. H. Chen, D. Nordlund, M. F. Toney, J. S. Huang and Z. N. Bao, Nat. Commun., 2014, 5, 3005.

18 C. Luo, A. K. K. Kyaw, L. A. Perez, S. Patel, M. Wang, B. Grimm, G. C. Bazan, E. J. Kramer and A. J. Heeger, Nano Lett., $2014,14,2764-2771$. 
19 G. Kim, S. J. Kang, G. K. Dutta, Y. K. Han, T. J. Shin, Y. Y. Noh and C. Yang, J. Am. Chem. Soc., 2014, 136, 9477-9483.

20 J. Y. Back, H. Yu, I. Song, I. Kang, H. Ahn, T. J. Shin, S. K. Kwon, J. H. Oh and Y. H. Kim, Chem. Mater., 2015, 27, 17321739.

21 J. Liu, H. L. Dong, Z. R. Wang, D. Y. Ji, C. L. Cheng, H. Geng, H. T. Zhang, Y. G. Zhen, L. Jiang, H. B. Fu, Z. S. Bo, W. Chen, Z. G. Shuai and W. P. Hu, Chem. Commun., 2015, 51, 11777 11779 .

22 T. D. Anthopoulos, B. Singh, N. Marjanovic, N. S. Sariciftci, A. M. Ramil, H. Sitter, M. Colle and D. M. de Leeuw, Appl. Phys. Lett., 2006, 89, 213504.

23 D. Shukla, S. F. Nelson, D. C. Freeman, M. Rajeswaran, W. G. Ahearn, D. M. Meyer and J. T. Carey, Chem. Mater., 2008, 20, 7486-7491.

24 H. Y. Li, B. C. K. Tee, J. J. Cha, Y. Cui, J. W. Chung, S. Y. Lee and Z. N. Bao, J. Am. Chem. Soc., 2012, 134, 2760-2765.

25 N. A. Minder, S. Ono, Z. H. Chen, A. Facchetti and A. F. Morpurgo, Adv. Mater., 2012, 24, 503-508.

26 A. F. Lv, S. R. Puniredd, J. H. Zhang, Z. B. Li, H. F. Zhu, W. Jiang, H. L. Dong, Y. D. He, L. Jiang, Y. Li, W. Pisula, Q. Meng, W. P. Hu and Z. H. Wang, Adv. Mater., 2012, 24, $2626-$ 2630.

27 B. D. Naab, S. Himmelberger, Y. Diao, K. Vandewal, P. Wei, B. Lussem, A. Salleo and Z. N. Bao, Adv. Mater., 2013, 25, 4663 4667.

28 T. Lei, J. H. Dou, X. Y. Cao, J. Y. Wang and J. Pei, Adv. Mater., 2013, 25, 6589-6593.

29 J. Lee, A. R. Han, H. Yu, T. J. Shin, C. Yang and J. H. Oh, J. Am. Chem. Soc., 2013, 135, 9540-9547.

30 F. J. Zhang, Y. B. Hu, T. Schuettfort, C. A. Di, X. K. Gao, C. R. McNeill, L. Thomsen, S. C. B. Mannsfeld, W. Yuan, H. Sirringhaus and D. B. Zhu, J. Am. Chem. Soc., 2013, 135, 23382349.

31 D. Q. Liu, Z. K. He, Y. R. Su, Y. Diao, S. C. B. Mannsfeld, Z. N. Bao, J. B. Xu and Q. Miao, Adv. Mater., 2014, 26, 71907196.

32 T. He, M. Stolte, C. Burschka, N. H. Hansen, T. Musiol, D. Kalblein, J. Pflaum, X. T. Tao, J. Brill and F. Wurthner, Nat Commun., 2015, 6, 5954

33 H. Sirringhaus, Nat. Mater., 2003, 2, 641-642.

34 Z. N. Bao and J. Locklin, Organic Field-Effect Transistors, CRC Press, Boca Raton, FL, 2007.

35 J. Zaumseil and H. Sirringhaus, Chem. Rev., 2007, 107, 12961323.

36 D. M. deLeeuw, M. M. J. Simenon, A. R. Brown and R. E. F. Einerhand, Synth. Met., 1997, 87, 53-59.

37 L. L. Chua, J. Zaumseil, J. F. Chang, E. C. W. Ou, P. K. H. Ho, H. Sirringhaus and R. H. Friend, Nature, 2005, 434, 194-199.

38 T. Takahashi, T. Takenobu, J. Takeya and Y. Iwasa, Appl. Phys. Lett., 2006, 88, 033505.

39 T. Uemura, M. Yamagishi, Y. Okada, K. Nakayama, M. Yoshizumi, M. Uno and J. Takeya, Adv. Mater., 2010, 22, 39383941.

40 M. C. Gwinner, Y. Vaynzof, K. K. Banger, P. K. H. Ho, R. H. Friend and H. Sirringhaus, Adv. Funct. Mater., 2010, 20, $3457-$ 3465 .

41 F. Cicoira, C. M. Aguirre and R. Martel, ACS Nano, 2011, 5, 283-290.

42 Y. H. Zhou, C. Fuentes-Hernandez, J. Shim, J. Meyer, A. J. Giordano, H. Li, P. Winget, T. Papadopoulos, H. Cheun, J. Kim, M. Fenoll, A. Dindar, W. Haske, E. Najafabadi, T. M. Khan, H. Sojoudi, S. Barlow, S. Graham, J. L. Bredas, S. R. Marder, A. Kahn and B. Kippelen, Science, 2012, 336, 327-332.

43 W. Xie, P. L. Prabhumirashi, Y. Nakayama, K. A. McGarry, M. L. Geier, Y. Uragami, K. Mase, C. J. Douglas, H. Ishii, M. C. Hersam and C. D. Frisbie, ACS Nano, 2013, 7, 10245-10256.
44 M. L. Tang, A. D. Reichardt, P. Wei and Z. N. Bao, J. Am. Chem. Soc., 2009, 131, 5264-5273.

45 Z. X. Liang, Q. Tang, J. B. Xu and Q. Miao, Adv. Mater., 2011, 23, 1535-1539.

46 J. G. Mei, Y. Diao, A. L. Appleton, L. Fang and Z. N. Bao, J. Am. Chem. Soc., 2013, 135, 6724-6746.

47 G. B. Xue, C. C. Fan, J. K. Wu, S. Liu, Y. J. Liu, H. Z. Chen, H. L. Xin and H. Y. Li, Mater. Horiz., 2015, 2, 344-349.

48 J. E. Anthony, J. S. Brooks, D. L. Eaton and S. R. Parkin, J. Am. Chem. Soc., 2001, 123, 9482-9483.

49 G. Giri, E. Verploegen, S. C. B. Mannsfeld, S. Atahan-Evrenk, D. H. Kim, S. Y. Lee, H. A. Becerril, A. Aspuru-Guzik, M. F. Toney and Z. N. Bao, Nature, 2011, 480, 504-508.

50 C. Z. Li, C. C. Chueh, H. L. Yip, F. Z. Ding, X. S. Li and A. K. Y. Jen, Adv. Mater., 2013, 25, 2457-2461.

51 B. Lussem, M. L. Tietze, H. Kleemann, C. Hossbach, J. W. Bartha, A. Zakhidov and K. Leo, Nat. Commun., 2013, 4, 2775.

52 C. L. Wang, Z. X. Liang, Y. L. Liu, X. M. Wang, N. Zhao, Q. Miao, W. P. Hu and J. B. Xu, J. Mater. Chem., 2011, 21, 1520115204.

53 D. Q. Liu, X. M. Xu, Y. R. Su, Z. K. He, J. B. Xu and Q. Miao, Angew. Chem. Int. Ed., 2013, 52, 6222-6227.

54 H. Y. Li, C. C. Fan, M. Vosgueritchian, B. C. K. Tee and H. Z. Chen, J. Mater. Chem. C, 2014, 2, 3617-3624.

55 S. Liu, J. K. Wu, C. C. Fan, G. B. Xue, H. Z. Chen, H. L. Xin and H. Y. Li, Sci. Bull., 2015, 60, 1122-1127.

56 H. Y. Li, C. C. Fan, W. F. Fu, H. L. Xin and H. Z. Chen, Angew. Chem. Int. Ed., 2015, 54, 956-960.

57 FETs were heated at various temperature of $80{ }^{\circ} \mathrm{C}, 100{ }^{\circ} \mathrm{C}$ and $120^{\circ} \mathrm{C}$ (Fig. S4 $\dagger$ ). The highest mobility was found at the heating temperature of $100^{\circ} \mathrm{C}$

58 V. Podzorov, MRS Bull., 2013, 38, 15-24.

59 P. M. Borsenberger and H. Bässler, J. Chem. Phys., 1991, 95, 5327-5331.

60 J. Veres, S. D. Ogier, S. W. Leeming, D. C. Cupertino and S. M. Khaffaf, Adv. Funct. Mater., 2003, 13, 199-204.

61 I. N. Hulea, S. Fratini, H. Xie, C. L. Mulder, N. N. Iossad, G. Rastelli, S. Ciuchi and A. F. Morpurgo, Nat. Mater., 2006, 5, 982-986.

62 V. Coropceanu and J. L. Bredas, Nat. Mater., 2006, 5, 929-930. 


\section{Graphical Abstract}

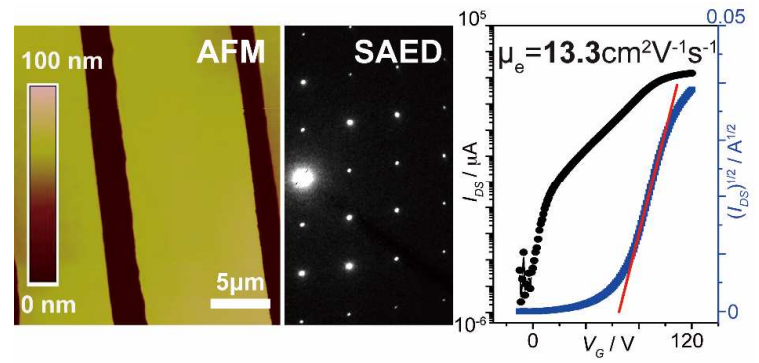

Electron mobility of solution-grown TIPS-TAP single crystals is boosted up to $13.3 \mathrm{~cm}^{2} \mathrm{~V}^{-1} \mathrm{~s}^{-1}$, after removing the polar solvent residues. 